\title{
Mecanismos de Participação e Atores Sociais em Hospitais: o caso do Grupo Hospitalar Conceição-RS'
}

\section{Social Actors and Participatory Mechanisms in Hospitals: the case of Grupo Hospitalar Conceição-RS}

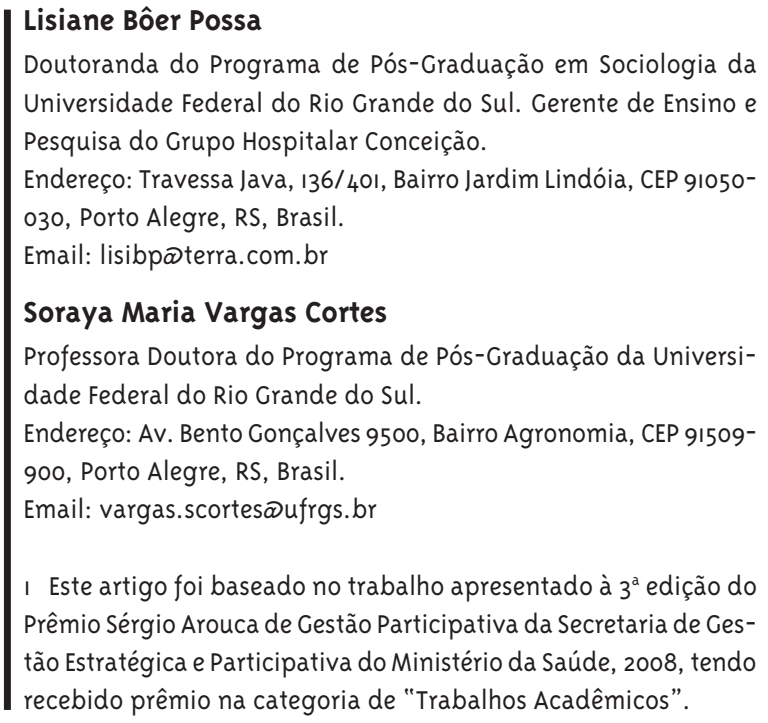

Doutoranda do Programa de Pós-Graduação em Sociologia da Universidade Federal do Rio Grande do Sul. Gerente de Ensino e Pesquisa do Grupo Hospitalar Conceição.

Endereço: Travessa Java, 136/40I, Bairro Jardim Lindóia, CEP 91050030, Porto Alegre, RS, Brasil.

Email: lisibpœterra.com.br

\section{Soraya Maria Vargas Cortes}

Professora Doutora do Programa de Pós-Graduação da Universidade Federal do Rio Grande do Sul.

Endereço: Av. Bento Gonçalves 9500, Bairro Agronomia, CEP 91509900, Porto Alegre, RS, Brasil.

Email: vargas.scortesळufrgs.br

1 Este artigo foi baseado no trabalho apresentado à $3^{\text {a }}$ edição do Prêmio Sérgio Arouca de Gestão Participativa da Secretaria de Gestão Estratégica e Participativa do Ministério da Saúde, 2008, tendo recebido prêmio na categoria de "Trabalhos Acadêmicos".

\section{Resumo}

O artigo tem como objetivo compreender o surgimento de mecanismos de participação em organizações hospitalares. Mais especificamente, procura identificar o papel e o impacto destes nas relações entre os atores no interior do hospital e em seu envolvimento com essa organização. A estratégia metodológica utilizada foi a de estudo de caso. O campo empírico foi o Grupo Hospitalar Conceição, em Porto Alegre/ RS. Através da pesquisa, pôde-se observar que os fóruns de participação existentes no hospital desempenham múltiplas funções, todas direcionadas para a inclusão dos usuários e trabalhadores de saúde na organização. Constituem-se como espaço para apresentação dos interesses, demandas e negociação de consensos. Abrem a agenda da Direção para temas relevantes para os atores participantes. Possibilitam tornar público o debate das questões polêmicas. Favorecem a construção de alianças entre os atores e a construção de apoio político para o enfrentamento de questões em disputa. Contribuem para a aprendizagem dos atores, a diminuição das assimetrias entre eles e a socialização das informações sobre o hospital. A existência de fóruns de participação contribuiu para alterar o envolvimento dos atores com o hospital e as relações entre eles. Pôde-se perceber que a criação de dispositivos de participação no hospital propiciou aos atores tradicionalmente excluídos e com menores recursos de poder, ou seja, usuários e trabalhadores de saúde, tanto maior envolvimento quanto relações mais horizontais com os demais atores. Ao mesmo tempo, diminuiu a intervenção dos médicos na organização com o fortalecimento da administração em aliança com esses outros atores.

Palavras-chave: Participação; Participação em hospital; Hospitais; Políticas de saúde. 


\section{Abstract}

The paper aims at understanding the role of participatory mechanisms in hospital organizations. It is a case study, looking at the role and impact of these mechanisms in the Grupo Hospitalar Conceição, in Porto Alegre/RS. Participatory mechanisms were situated at different levels in hospital organization, and were all of them directed to increased participation of users and health workers. They are spaces where participants present their interests and demands and consensus is negotiated. There, themes of participants' interests could be included at the hospital agenda, whilst polemic issues were publicly discussed. These instances of debate favor alliances among different actors; they help building up political support for the hospital decisions the forums agreed with, contribute to the actors learning, facilitate the lessening of power asymmetries in the hospital's decision making process; finally, they help the diffusion of information about the hospital in society. Since their institution, there was an increase in users and health workers involvement with hospital matters, while the relationship among these actors was intensified. The participatory mechanisms motivated some degree of openness towards actors which were traditionally excluded from decision making processes in hospitals: users and health workers. At the same time, it diminished the power of medical professionals, favoring an alliance between hospital administration and those newcomer actors.

Keywords: Participation; Participation in Hospitals; Hospitals; Health Policy.

\section{Introdução}

O tema deste artigo é a criação de mecanismos de participação em hospitais e o seu funcionamento. 0 problema da pesquisa que orientou a investigação foi o papel que os mecanismos de participação coletivos, abertos para novos atores, desempenham nestas organizações. Para responder à problemática, foram elaboradas as seguintes indagações: 1) Quem são os atores com poder nesses fóruns? 2) Como os fóruns influenciam os processos decisórios do hospital? 3) Qual a influência dos fóruns sobre o envolvimento dos atores com a instituição? 4) Qual o impacto dos fóruns nas relações entre atores?

A pesquisa adotou como estratégia de investigação o estudo de caso de uma organização hospitalar: o Grupo Hospitalar Conceição (GHC). O GHC é o maior complexo de saúde do sul do país, responsável pela assistência de parcela significativa da população da região metropolitana de Porto Alegre e referência em algumas especialidades para todo o estado do Rio Grande do Sul.

Os mecanismos de participação coletiva encontrados no GHC e que foram objeto desta análise são o Conselho Gestor, o Conselho de Administração e o Plano de Investimento. Para a coleta dos dados sobre os mesmos, utilizou-se a triangulação de várias técnicas. Foram coletados dados secundários, como documentos do GHC sobre os fóruns participativos instituídos, atas, resoluções e demais materiais escritos sobre ou pelos fóruns de participação. Foram realizadas entrevistas semi-estruturadas com os dirigentes e formuladores das políticas do GHC e com os atores envolvidos nos fóruns de participação. Outra fonte de informação foram observações do funcionamento dos fóruns existentes.

Para o tratamento analítico dos dados, o referencial teórico empregado foi proveniente das teorias das organizações, principalmente estudos que analisam a instituição hospitalar, e do debate sobre o conceito de instituições no âmbito do neoinstitucionalismo. Para estudar a participação nos hospitais, é necessário compreender o que é um hospital.

Essa questão, em um primeiro momento, parece carecer de sentido, visto que o hospital apresenta-se praticamente como um conceito auto-explicativo - o 
lugar da cura. Sob uma perspectiva histórica, nem sempre foi dessa forma; mesmo na atualidade essa organização tem sido questionada. 0 objetivo aqui é fazer algumas reflexões à luz da teoria para se construir a noção de hospital com que este estudo trabalhou e compreender melhor esta organização.

\section{O Hospital e a Participação}

As teorias das organizações auxiliam nesta análise. Através delas, é possível superar a visão de que as organizações são naturais e auto-evidentes, inserindoas no contexto histórico, como resultado de processos sociais nos quais atores tornam-se agentes e realizam escolhas. Essas teorias apontam a necessidade de que as organizações sejam compreendidas como produtos sociais que se instituem sob condições históricas específicas e no contexto de relações de poder particulares (Alvesson e Deetz, 2006).

As organizações são tanto objetos empíricos, no sentido de objetos da realidade, quanto um discurso teórico, visto que seus aspectos organizacionais são representados. Os meios de representação, as características julgadas salientes, tanto as explicitadas quanto as ignoradas, não são atributos da organização, mas das representações que dela se fazem. As organizações são processos sociais, locais das ações sociais dos indivíduos (Clegg e Hardy, 2006).

Nesta pesquisa, considera-se que as formas e práticas organizacionais são resultado dos conflitos, contradições e ambigüidades dos interesses dos atores agindo em seu interior, mas estas não se explicam apenas no comportamento organizacional. Estão relacionadas aos contextos macrossociológicos dos processos culturais e políticos em que são construídos e mobilizados os interesses e valores dos atores que defendem e constroem certas lógicas organizacionais e não outras. Nesse sentido, a (re) produção local de práticas nas organizações precisa ser explicada através dos padrões institucionalizados macrossocialmente que definem o papel e as características fundamentais dessa organização em uma dada sociedade, historicamente determinada, bem como pelos valores e interesses de atores individuais e coletivos dessa sociedade, que agem no interior dessa organização ou se relacionam com ela.
Dessa forma, para se entender a participação no hospital é necessário verificar tanto a prática de participação nos mecanismos participativos examinados quanto as racionalidades e as estruturas institucionais mais gerais que afetam essas práticas. A participação como possibilidade de interferir nos processos de decisão da organização é tanto resultado da ordem negociada entre os atores quanto de suas perspectivas de controle e de suas estratégias de poder (Reed, 2006).

Segundo Hall e Taylor (2003), para o institucionalismo, as instituições são o resultado dos conflitos de interesses entre os grupos sociais pelos recursos que são escassos. No estudo do funcionamento e do desenvolvimento das instituições, os analistas que se utilizam desta abordagem teórica buscam apreender como estas estruturam a repartição de poder de forma desigual entre os indivíduos e grupos sociais, ou seja, como ocorrem as assimetrias de poder.

Para os institucionalistas históricos, o olhar sobre o desenvolvimento institucional precisa considerar as trajetórias e as situações críticas. Eles defendem uma causalidade social dependente da trajetória percorrida, "path dependent", pois as instituições seriam como paisagens relativamente permanentes e um dos principais fatores que mantêm o desenvolvimento histórico sobre um conjunto de "trajetos". Nesse sentido, consideram que as políticas herdadas estruturam as decisões ulteriores, ou seja, as políticas adotadas no passado condicionam as futuras, ao encorajarem as forças sociais a se organizarem segundo certas orientações de preferência a outras, a adotarem identidades particulares. No entanto, estes autores reconhecem e buscam distinguir, no fluxo dos eventos históricos, períodos de continuidade e "situações críticas", que são os momentos nos quais mudanças institucionais importantes se produzem, criando desse modo bifurcações que conduzem o desenvolvimento de um novo trajeto que, segundo os institucionalistas históricos, surgem pelo desenvolvimento econômico-social e pelo aparecimento de novas idéias (Hall e Taylor, 2003).

Em primeiro lugar, é necessário esclarecer que se parte do princípio de que o hospital é uma organização marcada por uma elevada institucionalização de regras, de protocolos, procedimentos e convenções 
oficiais e oficiosas, que estruturam não apenas a forma como se promove o cuidado como também uma hierarquia social rígida que tem em seu topo o poder médico e da administração - freqüentemente articulados - e em seu estrato inferior os usuários de seus serviços. As origens da institucionalização das regras e convenções (Hall e Taylor, 2003) sobre como se organiza a cura nos hospitais e sobre como se estruturam as assimetrias de poder nessas organizações remontam à criação do hospital moderno.

O hospital moderno desenvolveu-se a partir de seu ancestral medieval. O hospital era, então, um local de exclusão para aqueles vistos como inadequados ao convívio social; era um espaço de "reclusão" para os indivíduos que temporariamente ou de forma crônica ameaçavam a ordem social. O encontro das ordens médica e hospitalar, conforme Foucault (1989), cria o hospital moderno: disciplinador dos corpos doentes, tendo os médicos como "guardiões" do cuidado. Esse hospital, dirigido pelo olhar esquadrinhador e disciplinador da clínica médica que comanda as ações da equipe de saúde, foi essencial para a experimentação e exercício do bio-poder sobre os corpos enfermos. Por meio dele, institucionalizou-se uma estrutura assimétrica de decisão sobre o cuidado em saúde e sobre como administrá-lo que é legitimada no saber médico e que define o modo como se organiza a atenção à saúde.

A organização hospitalar tende, portanto, a garantir um acesso rigidamente desigual dos indivíduos e grupos aos processos de decisão sobre o adoecimento e o cuidado. A inclusão de novos participantes nesses processos através de dispositivos de participação coletiva é uma mudança que, nesta análise, é vista como resultado de lutas pelo poder organizacional. Porém, assume-se também, no artigo, que os mecanismos participativos recentemente criados nos hospitais são o resultado de mudanças institucionais que têm redefinido a estratificação social interna dos hospitais.

Dentre as mudanças observadas, destacam-se: o fortalecimento das posições de administradores hospitalares e financiadores de serviços de saúde, públicos e privados, em detrimento do poder médico; a inclusão de novos profissionais, com a criação a partir dos anos 1950 de várias profissões que atuam na saúde; o direito à participação dos usuários, pre- visto no regramento do sistema de saúde brasileiro (Almeida, 1997; Costa e col., 200o; Roggenkamp e White, 2001; Vecina Neto e Malik, 2007).

A permanência do hospital como organização central do sistema de cuidados de saúde, nas sociedades contemporâneas, deve-se também a mudanças institucionais protagonizadas por atores coletivos e individuais. Segundo o institucionalismo histórico, a mudança, criação, manutenção e o papel das instituições podem ser explicados tanto por meio de uma perspectiva racional-utilitária quanto cultural. No primeiro caso, considera-se que as instituições se mantêm e se modificam para responder às problemáticas coletivas, trazendo benefícios aos atores sociais. No segundo, considera-se que as instituições fornecem modelos cognitivos e morais que permitem a interpretação e a ação, afetando a identidade, a imagem de si e as preferências que guiam a ação dos atores (Hall e Taylor, 2003).

A combinação das duas perspectivas ajuda a entender como as instituições, por intermédio da normatização das ações dos indivíduos, constrangem os atores, predispondo-os a agir de certo modo. Porém, ao optar por certos cursos de ação, as escolhas podem não estar seguindo imperativos culturais, e sim visar o fortalecimento de suas posições sociais e maximização de seus interesses. Dessa forma, a mudança na estratificação do poder no hospital é um produto da ação de atores - no caso administradores hospitalares, trabalhadores de saúde e usuários - que, ao refletir possíveis estratégias de ação em um contexto institucional cambiante, optam por aliar-se. Os mecanismos participativos se constituem como arenas nas quais tais alianças se estabelecem para o fortalecimento das posições dos aliados na estrutura organizacional.

Assim, apesar da tendência à permanência das instituições, elas mudam e provocam alterações no interior de organizações, como o demonstra a criação de mecanismos participativos em hospitais no Brasil. São poucas as organizações hospitalares que criaram esses dispositivos de participação em seu interior. A opção pela criação de mecanismos participativos nos hospitais, no entanto, é também corolário do contexto de reforma do sistema de saúde em curso no país desde a década de 80 do século XX. 
A $8^{a}$ Conferência Nacional de Saúde, realizada em 1986, a Constituição de 1988 , as Leis nº 8080 e n ${ }^{\circ} 8142$ de 1990 são os marcos fundamentais da reorganização do sistema de saúde. Os princípios e as diretrizes, expressos na Constituição (Brasil, 1988) e nas leis complementares são universalidade de acesso, integralidade, eqüidade na assistência, participação popular, descentralização da gestão, regionalização da atenção (Brasil, 1990a; 199ob). Ou seja, supera-se legalmente o modelo anterior de acesso a serviços de saúde que distinguia "indigentes" e "contribuintes"; a saúde se insere entre os direitos sociais dos cidadãos brasileiros; ao menos em uma perspectiva normativa, os usuários são todos iguais e lhes é constitucionalmente garantida a participação no sistema de saúde e em seu próprio cuidado.

Dentre as diretrizes do Sistema Único de Saúde (SUS), destaca-se a participação social no sistema. O cumprimento da diretriz da participação da comunidade na saúde e a ação dos atores que defendem esta proposta tiveram como resultado mais visível a construção dos conselhos e a realização de conferências de saúde.

Esses fóruns, por determinação legal, são compostos por representantes de governos, de trabalhadores de saúde, de prestadores de saúde entre eles os hospitais - e de usuários do sistema. A participação dos usuários no processo de decisão política do sistema de saúde se propunha como um mecanismo de regulação pública e deliberação sobre as formulações. A criação destes fóruns em todo o território nacional possibilitou que usuários dos serviços, gestores do sistema, trabalhadores de saúde e prestadores de serviços se envolvessem em discussões sobre a política de saúde e participassem na elaboração de propostas sobre o funcionamento do sistema.

Dentre essas propostas de funcionamento, destacam-se as deliberações das Conferências Nacionais de Saúde, que, a partir de 1996, determinam que os serviços de saúde, inclusive os hospitais, tenham conselhos gestores e outros mecanismos que possibilitem a participação dos diversos atores do sistema com capacidade de interferência nos rumos dos serviços e das organizações hospitalares (Brasil, 1998).
Os hospitais caracterizam-se por uma relativa autonomia frente aos conselhos e às conferências de saúde e mesmo em relação à regulação estatal. O poder dos médicos e dos administradores a eles aliados nas organizações hospitalares - legitimados pelo conhecimento técnico e administrativo especializado - confere aos hospitais certa autonomia frente aos controles governamentais, sobre como se organizar para o tratamento das doenças. A hegemonia desses profissionais restringe os recursos de poder dos demais atores envolvidos com os hospitais, sejam eles usuários, atores estatais, administradores hospitalares que se contrapõem ao poder médico e os outros trabalhadores de saúde.

Com o objetivo de reduzir tal autonomia e fomentar a participação de usuários e trabalhadores de saúde nos hospitais, atores estatais do Ministério da Saúde, identificados com o movimento sanitário, formularam em 200o, o Programa Nacional de Humanização da Assistência Hospitalar (PNHAH). Dentre as proposições do PNHAH, está a criação de mecanismos de escuta, tais como ouvidorias, pesquisa de satisfação, grupos de voluntários, entre outros (Brasil, 2001).

A política de gestão participativa do SUS começou a ganhar contornos mais nítidos a partir da criação da Secretaria de Gestão Participativa na estrutura do Ministério da Saúde em 2003. Em junho de 2005, esta Secretaria foi reorganizada como Secretaria de Gestão Estratégica e Participativa e assim institucionalizada pelo Decreto $\mathrm{n}^{0} 5.840$ de 13/o7/o6 da Presidência da República (Brasil, 2006a).

A Política Nacional de Gestão Estratégica e Participativa do SUS (ParticipaSUS) definiu o conceito de gestão participativa como uma noção abrangente de envolvimento individual e coletivo de diferentes atores, em momentos do processo de construção do cuidado que vão desde as decisões sobre políticas - dentro e fora do setor da saúde, em ambientes estatais e societais - ao cotidiano das unidades de saúde (Brasil, 20o6b).

O ParticipaSUS fundamenta-se principalmente nas deliberações da $12^{\text {a }}$ Conferência Nacional de Saúde, na legislação do SUS e no atual Plano Nacional da Saúde (PNS), que identifica a necessidade de fortalecimento das instâncias de controle social 
realizado pelos Conselhos de Saúde e propõe a capacitação dos diversos segmentos que os compõem. 0 Ministério da Saúde vem propondo a implantação de conselhos de gestão nos estabelecimentos de saúde ambulatoriais e hospitalares, públicos, conveniados e contratados (Brasil, 2006b). O ParticipaSUS preconiza também a qualificação e promoção da humanização e da solidariedade nas relações entre gestores, trabalhadores de saúde e usuários, ampliando desta forma os canais de comunicação e a co-responsabilidade desses atores com o processo de produção social da saúde, da garantia do acesso integral e da equidade (Brasil, 2006b).

A proposição de contratualização dos hospitais de ensino, em um primeiro momento, e dos hospitais filantrópicos, mais recentemente, aponta para uma outra forma de relação entre os atores estatais e organizacionais dos hospitais. A realização de contrato busca substituir a relação de financiamento por procedimento pelo estabelecimento de metas e objetivos que estas organizações devem alcançar. Esta proposição tem a intenção de ampliar a capacidade dos atores estatais influenciarem no planejamento e na oferta de serviços dessas organizações. Dentre as diretrizes propostas pelo Ministério para a formatação do contrato nestes hospitais está a inclusão de mecanismos de participação. No entanto, a existência da diretriz não significa a efetiva constituição de fóruns ou mecanismos de participação nos hospitais.

Os hospitais, mesmo públicos, cumprem o papel de prestadores de serviços relativamente autônomos em relação aos gestores públicos. Médicos e administradores hospitalares que a eles se aliam dominam a hierarquia de poder nos hospitais, e têm relativa autonomia em relação à regulação governamental para estabelecer políticas e prioridades dos serviços hospitalares. Através de diversos mecanismos de participação que foram sendo criados, os próprios gestores do sistema aliados a administradores hospitalares identificados com propostas reformistas, bem como a usuários e demais trabalhadores de saúde, procuram assegurar posições superiores na hierarquia social interna aos hospitais e aumentar sua influência sobre o processo decisório.

Essa constatação refere-se à perspectiva de que os atores políticos não podem ser classificados apenas como estatais ou societais. No caso da participação nos hospitais, é necessário distinguir ainda os atores organizacionais e não organizacionais. Os primeiros são os administradores aliados ao poder médico; administradores aliados à gestão governamental; poder médico - profissionais médicos que defendem a autonomia médica - e demais trabalhadores de saúde - profissionais de nível superior, tais como enfermeiros, fisioterapeutas, assistentes sociais, e trabalhadores de nível médio e elementar. Atores não organizacionais são os gestores do sistema de saúde - de nível federal, estadual e municipal - e os usuários.

Com base na leitura de autores como Arnstein (1969), Ham (1980), Lee e Mils (1985) e Paul (1987), Côrtes (1996) avalia que os mecanismos de participação podem resultar em diferentes tipos de envolvimento dos participantes nas instituições, como negociação, manipulação, delegação, consulta, informação e participação nos processos de decisão política. As diferentes possibilidades de envolvimento dos atores expressam as finalidades institucionais e políticas desses fóruns nos hospitais. A compreensão do papel que desempenham na organização para além do que normativamente está estabelecido pode ajudar a explicitar o tipo de envolvimento que dele resulta.

Macedo (2005) analisou a produção científica a respeito da participação e do controle social no setor saúde. A partir desse trabalho, pôde-se observar que as análises freqüentemente realizadas sobre os fóruns de participação na saúde tendem a investigar o quanto estes respondem ou não às normativas existentes. Ou seja, a que ponto os conselhos de saúde deliberam sobre as políticas segundo o previsto em lei, bem como os aspectos considerados limitadores para o desempenho desse papel.

Por outro lado, Côrtes e colaboradores (2006) identificam que o papel que os fóruns de participação desempenham nas organizações e no sistema não se restringem ao papel de deliberação nos processos decisórios. Segundo os autores,

eles podem se constituir como espaços nos quais as decisões já tomadas são legitimadas, negociam-se o estabelecimento de consensos, ocorrem disputas em torno de propostas conflituosas ou simplesmente arregimentam-se forças para disputas que, de 
fato, ocorrem em outros lugares (Côrtes e colaboradores, 2006, p. 99).

0 presente estudo assume que os processos de decisão no setor saúde ocorrem em diferentes espaços, não apenas nos fóruns de participação instituídos, e busca identificar qual o papel que os fóruns de fato desempenham no hospital, para além das prescrições normativas.

\section{Fóruns de Participação: como se organizam, quais os atores com poder, qual o poder e papel no hospital}

Foram analisados os mecanismos participativos em funcionamento no GHC em 2005 e 2006, quais sejam, o Conselho Gestor, o Conselho de Administração e o Plano de Investimento (Grupo Hospitalar Conceição [GHC], 2005, 2006a). O foco da análise recaiu sobre a caracterização e a distribuição dos atores no interior de cada mecanismo, e sobre e papel e a capacidade de influenciar o processo decisório organizacional.

O Conselho Gestor (CG) foi criado em 2004 através de portaria da direção do GHC, que resultou de negociação com o Conselho Municipal de Saúde de Porto Alegre, tendo sido aprovada nessa instância de controle social. O CG é um fórum permanente que tem a prerrogativa formal de deliberar sobre as questões do hospital. Tem como objetivo "[...] atuar na elaboração do planejamento, avaliação, fiscalização e controle da execução das políticas e das ações de saúde, inclusive em seus aspectos financeiros, em sua área de abrangência" (Grupo Hospitalar Conceição [GHC], 2004).

Compõe-se de 28 membros efetivos e igual número de suplentes, sendo 14 representantes de usuários, oito representantes escolhidos pelo Conselho Municipal e seis pelo Conselho Estadual de Saúde, 14 representantes do governo/prestadores/profissionais de saúde, quatro do corpo diretivo do GHC; um do Governo Municipal, um do Governo Estadual; um da Associação dos Prefeitos da Região Metropolitana de Porto Alegre - GRAMPAL, e sete das entidades associativas e sindicais dos trabalhadores do GHC (GHC, 2004).
Em síntese, o CG constitui-se em um espaço em que os usuários são os mais presentes e os atores que mais influem na formação da pauta de discussões. Os usuários são reconhecidos como os atores com poder no Conselho, mesmo pelos outros atores. A presença maior dos trabalhadores nas reuniões está associada à existência de pautas que lhes interessam. Todavia, pôde-se observar que a presença deles não altera o poder dos usuários, visto que vários temas debatidos tiveram encaminhamentos que não contemplavam o interesse dos trabalhadores, e estes acabaram por levar para outros fóruns o processo de decisão dessas questões. Pode-se formular a hipótese de que a pouca assiduidade nas reuniões de gestores e de administradores, reconhecidamente dotados de mais poder, contribui para que sejam os usuários os atores mais fortes nesse espaço.

De acordo com a análise das atas de reuniões e das entrevistas, o fórum influi mais nos processos administrativo-operacionais relacionados à gestão do cuidado, no âmbito das gerências estratégica, intermediária e das equipes e serviços. 0 poder do fórum no hospital consiste em influir nas questões relativas ao atendimento e organização dos serviços, em torno do que se concentram as demandas dos usuários. A pequena freqüência dos trabalhadores, a presença menor ainda dos administradores e gestores e o fato de que a resolução de conflitos muitas vezes não ocorre no âmbito do Conselho contribuem para a avaliação de que o poder do fórum na organização é limitado. O que, sem dúvida, o Conselho faz é consultar os representantes dos usuários sobre as suas demandas.

Por outro lado, foi possível verificar que o fórum cumpre um papel importante na inclusão dos usuários na gestão da organização. A existência do CG propiciou-lhes informação sobre o hospital e seu funcionamento, e ofereceu-lhes espaço para apresentarem organizadamente seus interesses e suas demandas, abrindo a agenda da Direção para as suas proposições.

O CG também cumpriu o papel de ser um canal de difusão de informação sobre o hospital para o conjunto de atores envolvidos. Possibilitou tornar público o debate em torno de questões polêmicas, tais como a transferência de serviços, o desligamento de trabalhadores aposentados e a mudança 
da figura jurídica do hospital. É um espaço em que ocorrem embates sobre questões em disputa entre os atores, em que estes explicitam seus interesses e suas visões sobre questões em conflito. Dessa forma, o Conselho tem possibilitado a construção de alianças entre atores para o enfrentamento das questões em disputa, arregimentando apoios para a tomada de decisões que ocorrem em outros espaços.

O Conselho de Administração (CA) é o órgão de deliberação máxima do GHC, em funcionamento desde sua origem, previsto nos estatutos das empresas que compõem o Grupo. Formalmente, devido à existência de três empresas de sociedade anônima, há três Conselhos de Administração no GHC. No entanto, na prática, trata-se de um mesmo fórum, que, devido às exigências legais, gera documentos específicos para cada uma de suas empresas.

A partir de 2003 , deu-se o cumprimento, previsto nos estatutos e até então não efetivado, da obrigatoriedade da presença do representante de trabalhadores, eleito diretamente entre seus pares. Além disso, segundo os estatutos, o Ministro da Saúde deve escolher como membro do Conselho de Administração "[...] brasileiros de notórios conhecimentos e experiência, idoneidade moral e reputação ilibada" (Grupo Hospitalar Conceição, GHC, 2006b). Esses representantes eram tradicionalmente escolhidos entre pessoas do Ministério da Saúde. Em 2003 isso se alterou e, ao lado destes, passaram a ter representação no Conselho o gestor municipal de saúde de Porto Alegre, o gestor estadual de saúde do Rio Grande do Sul e o Conselho Estadual de Saúde do Rio Grande do Sul, através de um representante de usuários. Desta forma, a composição do Conselho de Administração nos mandatos de 2003 a 2006 foi de três representantes do Ministério da Saúde, um do Ministério do Planejamento e Gestão, um de trabalhadores do Hospital, um da Secretaria Municipal de Saúde de Porto Alegre, um da Secretaria Estadual de Saúde do Rio Grande do Sul, um do Conselho Estadual de Saúde e o Diretor Superintendente do GHC.

Todos os participantes freqüentam as reuniões do Conselho. Sua composição poderia indicar que os gestores do sistema têm mais poder, visto que estão em maioria. No entanto, os administradores do hospital, em aliança com os gestores federais - particularmente com os representantes do Ministério da Saúde - são os atores que mais influência têm no fórum, sendo eles que definem a agenda de temas a serem discutidos. Os trabalhadores e usuários têm seu poder limitado pela carência de mais recursos de poder, o que expressa a assimetria nas relações de poder no fórum.

Apesar de envolver a alta gerência do Hospital e do sistema de saúde, a natureza da participação desse fórum, no contexto da organização do GHC, restringe-se a processos administrativos e operacionais. O CA, segundo os entrevistados, tem pouco poder sobre as questões relevantes do Hospital, ou seja, as decisões ali tomadas têm pouca influência sobre o processo decisório central da organização.

As principais funções do CA, identificadas nesta análise, são: a de reunir os atores do sistema de saúde e do hospital; a de possibilitar o acesso de seus participantes a informações; e a de propiciar maior conhecimento sobre a organização². Em especial, para os trabalhadores do Hospital, esse conhecimento sobre eventos e sobre a própria organização facilita a articulação com outros atores em outros espaços para, através da pressão, resistir a algumas decisões que contrariam seus interesses. Outro papel do fórum é o de legitimar, interna e externamente, as proposições e decisões tomadas pela administração do Grupo. O CA ainda oferece aos gestores federais aliados aos administradores que os apóiam suporte político para fazer frente aos gestores municipal e estadual e ao poder médico nos processos de decisão que ocorrem em outros lugares.

O Plano de Investimento (PI) é um dispositivo de participação criado no GHC desde o ano de 2003, quando os trabalhadores do Grupo e usuários passaram a participar do processo de definição dos investimentos dos hospitais e das unidades de saúde do GHC. Este processo é inspirado no Orçamento Participativo, praticado em Porto Alegre desde 1989, como alternativa de participação e democratização da forma de discussão dos investimentos no GHC (Ribeiro, 2005). 
O PI realiza-se em duas etapas anuais - a constituição de uma comissão eleita diretamente pelos trabalhadores por local de trabalho, que define os participantes do PI que representam os trabalhadores do Hospital, e o Fórum Geral dos Trabalhadores e Usuários. Os representantes destes últimos no PI são indicados pelo Conselho Municipal de Saúde de Porto Alegre e pelo Conselho Gestor do GHC.

Os participantes mais influentes no PI são os trabalhadores do Hospital. Apesar de contar com a presença de usuários e dos médicos, estes estão em minoria. Todas as decisões ali incidem na gestão financeira do Hospital. Uma vez definidas as propostas, há um processo de negociação entre trabalhadores e administradores do Hospital na definição dos investimentos a serem realizados. Nesse sentido, o PI é reconhecido como um importante mecanismo de participação no GHC, na medida em que, de fato, as deliberações do fórum orientam os investimentos realizados na organização.

Entre os papéis do PI identificados nessa análise, destaca-se a negociação de consensos entre os trabalhadores e administradores sobre as prioridades de investimentos. É reconhecido como um dispositivo que possibilita a aprendizagem dos atores e também considerado como um espaço que contribui para a diminuição das assimetrias dos trabalhadores entre si e com os médicos e administradores. Possibilita a expressão e o atendimento das demandas dos usuários, mas principalmente dos demais trabalhadores nas questões de infra-estrutura do hospital. Dessa forma, aproxima os investimentos realizados da realidade desses atores. É considerado um dispositivo que propicia a transparência no uso dos investimentos e no controle público dos mesmos.

\section{As Mudanças no Envolvimento com - Hospital e nas Relações entre os Atores}

Os fóruns de participação, criados a partir de 2003, contribuíram para alterar as relações entre os atores e estimularam o envolvimento de novos atores no processo decisório da organização. Cabe destacar que o grande poder de administradores e de médicos é reconhecido na maioria dos estudos realizados sobre os hospitais (Carapinheiro, 1998). Por isso, a questão aqui é verificar se outros atores, usuários, trabalhadores de saúde e gestores do sistema ampliam sua participação no processo decisório do hospital, a partir da existência de fóruns de participação formalizados.

Constatou-se que os fóruns contribuem para a alteração do envolvimento dos atores na organização. Os representantes de usuários deixaram de ser exclusivamente pacientes e doentes que precisavam de cuidados, para se transformarem em usuários do sistema de saúde em condições de apresentar propostas e reivindicar melhorias no atendimento de forma organizada. Os trabalhadores do Hospital passaram a se envolver com questões organizacionais mais amplas.

Os gestores de saúde em geral ampliaram seu envolvimento, ao obterem mais informações sobre o funcionamento do Hospital. Entretanto, os gestores federais em aliança com administradores identificados com suas propostas, reduziram a autonomia do Hospital frente à regulação governamental. A expansão da participação de outros atores no processo decisório da organização, via mecanismos participativos, propiciou, por vezes, que novas alianças fossem formadas em contraposição ao poder dos médicos e de administradores com eles identificados.

Os médicos tiveram a sua capacidade de interferir junto à administração diminuída, pois a existência dos fóruns não significou sua maior participação. Ao contrário: eles passaram a ter que dividir com outros atores a possibilidade de influenciar nas decisões organizacionais. Os administradores identificados com as propostas dos gestores federais de saúde, por sua vez, aumentaram sua capacidade de impor normas à organização e de tomar decisões frente aos médicos. Isso, ao menos em parte, deve-se às alianças com os demais atores estabelecidas nos espaços participativos aqui analisados.

Mudanças nas relações entre os atores no Hospital também são atribuídas aos fóruns de participação, embora não pareçam ter afetado a posição dos gestores do sistema. Os mecanismos de participação contribuíram para uma aproximação e mudança na relação entre os administradores do Hospital e as entidades que representam os trabalhadores de 
saúde. A Direção passou a escutá-los, e ampliaram-se os canais de dialogo. Isso não significa dizer que tais mecanismos acabaram com relações assimétricas e hierárquicas entre os trabalhadores de saúde e administradores no cotidiano do trabalho na instituição. 0 que houve foi a constituição de uma nova estratificação social no interior dos hospitais, na qual as posições dos atores internos e externos à organização se alteraram. Enquanto médicos e administradores hospitalares a eles aliados tiveram sua influência reduzida no processo decisório organizacional, bem como a autonomia de suas ações frente à regulação governamental, os trabalhadores de saúde, usuários, gestores federais e os administradores identificados suas propostas ampliaram a sua influência. Isso não quer dizer, entretanto, que o poder médico não permaneça no topo da hierarquia organizacional, e sim que sua posição relativa aos demais atores mudou, ao menos no que se refere a assuntos administrativos da organização.

Os fóruns de participação também contribuíram para alterar a relação dos médicos com os demais trabalhadores e usuários. Nesses espaços, são estabelecidas relações mais horizontais, visto que as diferenças de saberes, que sustentam em grande medida as relações de assimetria entre esses atores, se diluem quando todos podem vocalizar seus interesses publicamente. No entanto, não foi percebida influência dos fóruns nas relações entre médicos e demais trabalhadores no cotidiano do Hospital.

Houve alteração na relação entre os usuários e o conjunto dos atores organizacionais. A mudança foi atribuída à existência dos fóruns de participação no Hospital, na medida em que estes possibilitaram que os representantes de usuários fizessem demandas, apresentassem propostas e tivessem sua condição de interlocutor legítimo reconhecida. Os dispositivos de participação lhes permitiram apresentar suas demandas e opiniões e questionar os atores com mais poder, médicos, administradores e demais trabalhadores, a partir de um lugar público e mais protegido, ou seja, no qual tais atores são constrangidos a não utilizar esse poder.

Apesar de não atingir a todos e em todos os momentos, a institucionalização da participação dos usuários, a abertura de canais de escuta e o reconhecimento de suas posições através dos fóruns contri- buiu sem dúvida para mudar, em alguma medida, a relação desses atores com os demais, promovendo relações mais horizontais e de menor dominação nas relações cotidianas do hospital.

\section{Considerações Finais}

Respondendo às questões desta pesquisa, pôde-se verificar que, no caso estudado, a existência de fóruns de participação contribuiu para alterar o envolvimento dos atores com o Hospital e as relações entre eles. Foi possível perceber que a criação de dispositivos de participação no Hospital propiciou aos atores tradicionalmente excluídos e com menores recursos de poder, ou seja, usuários e demais trabalhadores, tanto maior envolvimento como relações mais horizontais com os demais atores. Ao mesmo tempo, diminuiu a intervenção dos médicos na organização com o fortalecimento da administração em aliança com outros atores.

É importante salientar que, sendo este um estudo pioneiro sobre fóruns coletivos de participação em hospital, a descrição dos fóruns e do papel que eles desenvolvem, neste caso específico, não tem a pretensão afirmativa e de generalização, sendo fundamentais outros estudos com foco nessas organizações. No entanto, pode-se observar que os três mecanismos de participação estudados são dispositivos que fazem parte do processo decisório da organização. Ao terem como papel a construção de alianças e de consensos, a escuta dos diferentes interesses, a explicitação pública dos conflitos e a busca de apoio político dos atores, tais instâncias fazem parte do contexto decisório, mesmo não sendo os espaços em que todas, ou mesmo as principais deliberações ocorram. Ou seja, mesmo não se tratando de mecanismos de participação que deliberem sobre a organização, estes fóruns fazem parte e contribuem para os processos decisórios.

Nesse aspecto, é relevante que se aprofundem as análises sobre os processos decisórios nos hospitais, a relação dos fóruns participativos com esses processos, as posições diferenciadas dos atores sobre a necessidade de fóruns de participação e a possibilidade de terem poder e influenciar os rumos da organização. As conclusões deste estudo sinalizam para outras pesquisas, pois as expectativas, identi- 
dades e estratégias de poder dos atores no hospital são aspectos que podem auxiliar na explicação de suas posições acerca dos fóruns participativos e de sua ação nesses espaços.

\section{Referências}

ALMEIDA, C. Médicos e assistência médica:

Estado, mercado ou regulação? Uma falsa questão. Cadernos de Saúde Pública, Rio de Janeiro, v. 13, n. 4, p. 659-676, out. 1997.

ALVESSON, M.; DEETZ, S. Teoria crítica e abordagens pós-modernas para estudos organizacionais. In: CLEGG, S. R.; HARDY, C.; NORD, W. R. (Orgs.) Handbook de estudos organizacionais: modelos de análises e novas questões em estudos organizacionais. São Paulo: Atlas, 2006. p. 226-264.

BRASIL. Constituição Federal (1988). Brasília, DF: Congresso Nacional, 1988.

BRASIL. Lei Federal no 8.o8o, de 19 de Setembro de 1990. Dispõe sobre as condições para a promoção, proteção e recuperação da saúde, a organização e o funcionamento dos serviços correspondentes e dá outras providências. Brasília, DF: Casa Civil, 1990a.

BRASIL. Lei Federal no 8.142, de 28 de Dezembro de 1990. Dispõe sobre a participação da comunidade na gestão do Sistema Único de Saúde (SUS) e sobre as transferências intergovernamentais de recursos financeiros na área da saúde e dá outras providências. Brasília, DF: Casa Civil, 199ob.

BRASIL. Ministério da Saúde. Relatório Final da $10^{a}$ Conferência Nacional de Saúde. Brasília, DF: Ministério da Saúde, 1998.

BRASIL. Ministério da Saúde. Programa Nacional de Humanização da Assistência Hospitalar. Brasília, DF: Ministério da Saúde, 2001.

BRASIL. Decreto $n^{\circ} 5.840$, de 13 de Julho de 2006. Institui, no âmbito federal, o Programa Nacional de Integração da Educação Profissional com a Educação Básica na Modalidade de Educação de Jovens e Adultos - PROEJA, e dá outras providências. Brasília, DF: Casa Civil, 20o6a.
BRASIL. Ministério da Saúde. Política Nacional de Gestão Estratégica e Participativa no SUS: ParticipaSUS. Brasília, DF: Ministério da Saúde, 2006b.

CARAPINHEIRO, G. Saberes e poderes no hospital: uma sociologia dos serviços hospitalares. 3. ed. Porto: Afrontamento, 1998.

CLEGG, S. R.; HARDY, C. Introdução: organização e estudos organizacionais. In: CLEGG, S. R.; HARDY, C.; NORD, W. R. (Orgs.). Handbook de estudos organizacionais: modelos de análises e novas questões em estudos organizacionais. São Paulo: Atlas, 2006. p. 29-58.

CÔRTES, S. M. V. Participação na área da saúde: o conceito, suas origens e seu papel em diferentes projetos de reformas do Estado. Saúde - Revista do NIPESC, Porto Alegre, Universidade Federal do Rio Grande do Sul, v. 1, p. 51-69, 1996.

CÔRTES, S. M. V. et al. Projeto Fortalecimento da Gestão Hospitalar para o Sistema Único de Saúde (SUS). Relatório de Pesquisa. Porto Alegre: Universidade Federal do Rio Grande do Sul, 2006.

COSTA, N. R.; RIBEIRO, J. M.; SILVA, P. L. B.

Reforma do estado e mudança organizacional: um estudo de hospitais públicos. Ciência \& Saúde Coletiva, Rio de Janeiro, v. 5, n. 2, p. 427-442, 2000 FOUCAULT, M. Microfísica do poder. 8. ed. Rio de Janeiro: Graal, 1989.

GRUPO HOSPITALAR CONCEIÇÃO. Portaria de Criação do Conselho Gestor $\mathrm{n}^{0} 174 / \mathrm{o} 4$, Porto Alegre: Grupo Hospitalar Conceição, 2004.

GRUPO HOSPITALAR CONCEIÇÃO. Plano Operativo 2005. Porto Alegre: Grupo Hospitalar Conceição, 2005.

GRUPO HOSPITALAR CONCEIÇÃO. Relatório de Gestão 2005. Porto Alegre: Grupo Hospitalar Conceição 2006a.

GRUPO HOSPITALAR CONCEIÇÃO. Estatuto social. Porto Alegre: Grupo Hospitalar Conceição, 2006b.

HALL, P. A.; TAYLOR, R. C. R. As três versões do neo-institucionalismo. Lua Nova, São Paulo, n. 58, p. 193-223, 2003 . 
MACEDO, L. C. Participação e controle social na área da saúde: uma revisão bibliográfica. 2005. 118f. Dissertação (Mestrado em Enfermagem) - Escola de Enfermagem de Ribeirão Preto, Universidade de São Paulo, Ribeirão Preto, SP, 2005 .

REED, M. Teorização organizacional: um campo historicamente contestado. In: CLEGG, S. R.; HARDY, C.; NORD, W. R. (Orgs.). Handbook de estudos organizacionais: modelos de análises e novas questões em estudos organizacionais. São Paulo: Atlas, 2006. p. 61-97.
RIBEIRO, Luis. Plano de Investimento do Grupo Hospitalar Conceição: democratização da gestão e transparência. Porto Alegre: Grupo Hospitalar Conceição, 2005.

ROGGENKAMP, S. D.; WHITE, K. R. Is hospital case management a rationalized myth? Social Science \& Medicine, Amsterdam, v. 53, n. 8, p. 10571066, 2001.

VECINA NETO, G.; MALIK, A. M. Tendências na assistência hospitalar. Ciência \& Saúde Coletiva, Rio de Janeiro, v. 12, n. 4, p. 825-839, ago. 2007. 